\title{
-Characterization of substrate specificity and novel autoprocessing mechanism of dipeptidase A from Prevotella intermedia
}

\author{
Mohammad Tanvir Sarwar ${ }^{1}$, Yuko Ohara-Nemoto ${ }^{1}$, Takeshi Kobayakawa ${ }^{1}$, \\ Mariko Naito ${ }^{2}$, and Takayuki K. Nemoto, ${ }^{1, *}$ \\ ${ }^{1}$ Department of Oral Molecular Biology, Course of Medical and Dental Sciences, Nagasaki University \\ Graduate School of Biomedical Sciences, Nagasaki 852-8588, Japan \\ ${ }^{2}$ Department of Microbiology and Oral Infection, Nagasaki University Graduate School of Biomedical \\ Sciences, Nagasaki 852-8588, Japan \\ ${ }^{*}$ Corresponding author. Takayuki K. Nemoto, Department of Oral Molecular Biology, Course of \\ Medical and Dental Sciences, Nagasaki University Graduate School of Biomedical Sciences, 1-7-1 \\ Sakamoto, Nagasaki 852-8588, Japan. Tel.: +81 95819 7640; Fax: +81 958197642 \\ E-mail address: tanvirsarwariu@gmail.com (M.T. Sarwar), ynemoto@nagasaki-u.ac.jp (Y. Ohara- \\ Nemoto), takecyan@nagasaki-u.ac.jp (T. Kobayakawa), mnaito@nagasaki-u.ac.jp (M. Naito), \\ tnemoto@nagasaki-u.ac.jp (T.K. Nemoto).
}

\begin{abstract}
Prevotella intermedia, a gram-negative anaerobic rod, is frequently observed in subgingival polymicrobial biofilm from adults with chronic periodontitis. Peptidases in periodontopathic bacteria are considered to function as etiological reagents. Pre. intermedia OMA14 cells abundantly express an unidentified cysteine peptidase specific for Arg-4-methycoumaryl-7-amide (MCA). BAU17746 (locus tag, PIOMA14_I_1238) and BAU18827 (locus tag, PIOMA14_II 0322) emerged as candidates of this peptidase from the substrate specificity and sequence similarity with C69-family Streptococcus gordonii Arg-aminopeptidase. The recombinant form of the former solely exhibited hydrolyzing activity toward Arg-MCA, and BAU17746 possesses a 26.6\% amino acid identity with the C69-family Lactobacillus helveticus dipeptidase A. It was found that BAU17746 as well as L. helveticus dipeptidase A was a P1-position Arg-specific dipeptidase A, although the L. helveticus entity, a representative of the C69 family, had been reported to be specific for Leu and Phe. The full-length form of BAU17746 was intramolecularly processed to a mature form carrying the N-terminus of Cys ${ }^{15}$. In conclusion, the marked Arg-MCA-hydrolyzing activity in Pre. intermedia was mediated by BAU17746 belonging to the C69-family dipeptidase A, in which the mature form carries an essential cysteine at the $\mathrm{N}$-terminus.
\end{abstract}

Keywords: dipeptidase A; cysteine peptidase, autoprocessing; Prevotella intermedia; substrate specificity; periodontal disease.

\section{Introduction}

Prevotella intermedia, a gram-negative anaerobic rod frequently noted in subgingival polymicrobial biofilms, was obtained from adults with chronic periodontitis (Rams and van Winkelhoff, 2017; Deng et al., 2017) and reported to be associated with periapical periodontitis (Gomes et al.,1994; 1996; Jacinto et al., 2003). This bacterium has also been detected in association with other oral conditions, including endodontic infections (Fukushima et al., 1990; Baumgartner et al., 1999), acute necrotizing 
ulcerative (Loesche et al., 1982), and pregnancy gingivitis (Raber-Durlacher et al., 1994). In addition, others have implicated that Pre. intermedia is closely related to systemic diseases, such as atherosclerosis, cardiovascular disease, and stroke (Scannapieco et al., 2003), as well as preterm birth (Offenbacher et al., 2001). Because of its versatile nature, Prevotella species have also been observed in the upper respiratory tract, urogenital tract (Eiring et al., 1998), and large intestine (Hayashi et al., 2007).

Peptidases produced by periodontopathic bacteria provide nutrients for bacterial growth, and are important etiologic reagents involved in degradation of periodontal tissues and alterations of the host immune system and bioactive peptides (Potempa et al., 2000). Notably, various studies regarding Argand Lys-specific gingipains of Porphyromonas gingivalis have been presented (Chen et al., 1992; Scott et al., 1993; Pike et al., 1994; Pavloff et al., 1995; 1997), and more recent reports of dipeptideproducing enzymes, known as dipeptidyl-peptidases (DPPs), and a novel acylpeptidyl oligopeptidase are considered to be essential for growth and pathogenicity of $P$. gingivalis (Nemoto and OharaNemoto, 2016; Nemoto et al., 2016; Ohara-Nemoto et al., 2017). In contrast to gingipains solely expressed in P. gingivalis, most DPP genes and their activities can be found in several periodontopathic bacteria including Pre. intermedia (Ohara-Nemoto et al., 2018). However, little is known about peptidases in Pre. intermedia yet, though it has been shown that the level of proteolytic activity in clinical strains was significantly higher than that in commensal strains isolated from healthy subjects (Yanagisawa et al., 2006). Pre. intermedia efficiently incorporates single amino acids and produces ammonia (Shah and Williams, 1987; Takahashi and Sato, 2001), thus peptidases related to release single amino acids are considered to be important.

In the present study, we identified the C69-family member dipeptidase A in Pre. intermedia BAU17746. Enzymatic and biochemical properties of this peptidase were compared with two additional C69-family members from Lactobacillus helveticus and Tannerella forsythia. The present results demonstrated that current understanding regarding the substrate specificity of the C69 family should be revisited. Moreover, we here report that the C69-family dipeptidase A is a unique cysteine peptidase with an essential cysteine at the N-terminus.

\section{Results}

\section{Exopeptidase activities of Pre. intermedia}

Peptidase activities of Pre. intermedia OMA14 were determined with phosphate-buffered saline (PBS)washed and resuspended cells by use of a series of fluorogenic peptidyl-4-methycoumaryl-7-amide (MCA) substrates (Figure 1). In our previous study, DPP4 from the bacterial strain has been cloned and characterized (Ohara-Nemoto et al., 2017, 2018). In addition, Phe-Met-MCA was established as a specific substrate for DPP7 (Nemoto et al., 2018), which enables determination of DPP7 activity separately from that of DPP5 in bacterial cells. Figure 1A indicated that the activities of DPP7 for PheMet-MCA and DPP4 for Gly-Pro-MCA were predominant, while some hydrolysis of Lys-Ala-MCA by DPP5 was detected. No hydrolysis of Leu-Asp- or Leu-Glu-MCA was observed, in accord with lack of the DPP11 gene in the genome (Naito et al., 2016).

Among 6 aminoacyl-MCA substrates (Arg, Lys, Leu, Met, Ala, Phe), predominant hydrolysis of Arg-MCA was observed, while other activities were markedly limited. In order to determine whether the Arg-MCA-hydrolyzing entity is mediated by either an exopeptidase or endopeptidase, hydrolyses of various MCA substrates carrying Arg at the P1 position were examined. As shown in Figure 1C, Pre. intermedia predominantly hydrolyzed Arg-MCA, whereas degradation of Arg-Arg-, $t$ butyloxycarbonyl-[(2S)-2-amino-3-(benzyloxycarbonyl) propionyl (Boc)-FSR-, and Boc-RVRR-MCA was limited, and hydrolysis of the remaining 5 substrates [benzoylglycyl (Bz)-Arg-, benzyloxycarbonyl (Z)-Leu-Leu-, glutalyl (Glt)-Gly-Arg-, Z-VVR-, pyroglutamyl (Pyr)-RTKR-MCA] was negligible. These results suggested that Arg-MCA-hydrolyzing activity was mediated by an Arg-specific aminopeptidase.

To characterize this hydrolyzing activity, we examined its biochemical properties. The activity was steeply increased in the presence of $3-30 \mathrm{mM}$ dithiothreitol, then elevation continued in a linear manner until $300 \mathrm{mM}$ (Figure 2A), suggesting that this entity is a cysteine peptidase. Cellular ArgMCA hydrolysis reached a plateau at $\mathrm{pH} 7.5$ in phosphate buffer, though was further increased when 
using Tris- $\mathrm{HCl}$ buffer (Figure 2B), suggesting that an alkaline $\mathrm{pH}$ level caused disruption of the cells. The Arg-MCA-hydrolyzing activity was scarcely detected in the culture supernatant. In contrast, that activity was observed in bacterial cells, with greater activity noted in the fraction comprising the cytosol and periplasm in the presence of dithiothreitol (Figure 2C).

\section{Expression and processing of BAU17746}

BAU17746 and BAU18827 in Pre. intermedia OMA14 have been annotated as C69-family cysteine peptidases (Naito et al., 2016) and showed amino acid sequence identity of $21.5 \%$ and $14.7 \%$, respectively, to Streptococcus gordonii Arg-aminopeptidase (MER002648) (Goldstein et al., 2002), the representative molecule of the C69.002 cysteine peptidase family. The amino acid identity between BAU17746 and BAU18827 was low (13.4\%) (Table 2). SignalP-5.0 search (http://www.cbs.dtu.dk/services/SignalP/) indicated the presence of a signal peptide in BAU18827

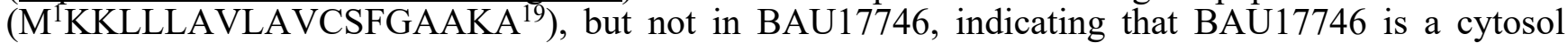
protein, but that BAU18827 is secreted.

There are two major subfamilies in the C69 family, i.e., C69.001 represented by L. helveticus dipeptidase A (Dudley et al., 1996; Vesanto et al., 1996) and C69.002 represented by S. gordonii Argaminopeptidase. Although other members, i.e., exocytosis regulator secernin and Drosophila melanogaster CG10098 protein are classified in other subfamilies C69.003-C69.006, their enzymatic properties are unknown (Way et al., 2002).

To examine peptidase activities of BAU17746 and BAU18827, their full-length recombinant forms with C-terminal His 6 tag were expressed in Escherichia coli. Purified proteins were separated with SDS-PAGE as 54- and 60-kDa species, respectively, in accordance with the calculated molecular masses (Figure 4A). We found that BAU17746 exhibited activity toward Arg-MCA, whereas that from BAU18827 did not show any hydrolysis (Figure 4B). Since $\mathrm{Cys}^{26}$ of $S$. gordonii Arg-aminopeptidase is an essential residue (Goldstein et al., 2002), we speculated that the equivalent Cys ${ }^{15}$ of BAU17746 is essential for its activity. In fact, both an N-terminal truncated form (BAU17746 $\Delta \mathrm{N} 1-35)$ and the C15A mutant (BAU17746C15A) completely lost Arg-MCA-hydrolyzing activity.

Recombinant BAU17746 revealed a faint 56-kDa band in addition to a major 54-kDa band (Figure 4A). N-terminal sequencing analysis demonstrated the N-terminus of the 54-kDa species as Cys ${ }^{15}$. On the other hand, the 56-kDa species was shown to be mainly composed of two species starting at Met ${ }^{1}$ of $^{-1}$ BAU17746 and Gly $^{-3}$ derived from pQE60, in addition to inevitable contamination of predominant 54$\mathrm{kDa}$ species with the N-terminus of $\mathrm{Cys}^{15}$ (Figure $4 \mathrm{C}$ ). Thus, these results suggest that the 54-kDa species from BAU17746 was a mature form with $\mathrm{Cys}^{15}$ as the N-terminus. Interestingly, the 54-kDa processed species was never produced in the BAU17746C15A.

This phenomenon was clearly reproduced on glutathione $S$-transferase (GST)-BAU17746 fusion protein and its C15A mutant. The $80-\mathrm{kDa}$ GST-BAU17746 was recovered as a minor species in the wild type, while 30- and 54-kDa species were dominant. An immunoblotting against anti-GST antibody demonstrated that $30-$ and $80-\mathrm{kDa}$ were GST proteins. Accordingly, the 54-kDa species corresponded to mature BAU17746 (Figure 5A). The specific activity ( $\mathrm{pmol} / \mathrm{min} / \mu \mathrm{g}$ protein) for ArgMCA of this preparation accounted for $30 \%$ of the wild type, which seemed to be reasonable, because it contains a considerable amount of GST and a minor unprocessed $80-\mathrm{kDa}$ fusion form (Figure 5A). In contrast, GST-BAU17746C15A carrying no peptidase activity was solely recovered as an 80-kDa species, confirming BAU17746-mediated processing at the Glu ${ }^{14}-\mathrm{Cys}^{15}$ bond.

We next determined the mechanism of the cleavage at the Glu ${ }^{14}-\mathrm{Cys}^{15}$ bond. Even though the 80$\mathrm{kDa}$ GST-BAU17746C15A was co-incubated with BAU17746 mature form at $37{ }^{\circ} \mathrm{C}$ for $5 \mathrm{~h}$, the degradation of the $80-\mathrm{kDa}$ species was neither observed, the $30-\mathrm{kDa}$ GST was nor produced, and no increase in the 54-kDa species was observed (Figure 5B). This finding strongly suggested that the cleavage at the $\mathrm{Glu}^{14}$-Cys ${ }^{15}$ bond was not intermolecularly processed by a mature form, but intramolecularly mediated by a proenzyme itself.

\section{Arg-MCA-hydrolyzing property of BAU17746}

The effects of reducing agents and protease inhibitors were examined with both Pre. intermedia cells and recombinant BAU17746. Arg-specific aminopeptidase activities were significantly enhanced with dithiothreitol and 2-mercaptoethanol in a dose-dependent manner, though the efficiency of 
dithiothreitol was superior, reflecting its higher reducing potential (Table 3). Moreover, the activities were completely inhibited by monoiodoacetic acid, a cysteine-blocking agent. To the contrary, the effects of serine and metallopeptidase inhibitors on the cellular activity and BAU17746 are limited. Taken together, these results confirmed that the Arg-MCA-hydrolyzing activity observed in Pre. intermedia is mediated by a cysteine peptidase, BAU17746.

Recombinant BAU17746 hydrolyzed Arg-MCA most efficiently, while hydrolysis of other aminoacyl- and peptidyl-MCAs was scarcely observed (Figure 6A, B). The activity was highly dependent on dithiothreitol concentration (Figure 6C), and the $\mathrm{pH}$ profile showed a peak at $\mathrm{pH} 8.5$ in Tris- $\mathrm{HCl}$ buffer, while the activity itself was higher at $\mathrm{pH} 7.7$ in sodium phosphate buffer (Figure 6D), which indicated that the amino group of tris-hydroxymethane aminomethane functions as a very weak inhibitor of Arg-specific peptidase. Accordingly, the peptidase activity of the recombinant forms was measured in $50 \mathrm{mM}$ sodium phosphate buffer at $\mathrm{pH} 7.7$ containing $60 \mathrm{mM}$ dithiothreitol in the following experiments. The $k_{\text {cat }}$ and $K_{\mathrm{m}}$ values of the peptidase for Arg-MCA were $0.012 \mathrm{~s}^{-1}$ and 1.67 $\mu \mathrm{M}$, respectively, thus that of $k_{\text {cat }} / K_{\mathrm{m}}$ was $0.0074 \mathrm{~s}^{-1} \mu \mathrm{M}^{-1}$.

We also examined the molecular status of the peptidase using size exclusion HPLC (Figure 6F). BAU17746 was eluted at the 450-kDa position with a preceding shoulder. In contrast, the cellular form was split into minor and major peaks of 350 and $120 \mathrm{kDa}$, respectively. Taken together, the peptidase seemed to mainly be presented as a dimer in an endogenous form, while recombinant peptidase showed a tendency to form at $8-10$-mers. We previously reported a similar phenomenon with acylpeptidyl oligopeptidase of $P$. gingivalis (Nemoto et al., 2016).

\section{Property of BAU17746 as dipeptidase A}

Our findings of partial hydrolysis of Arg-Arg-, Boc-FSR-, and Boc-RVRR-MCA were not reproduced by BAU17746 (compare Figures 1 and 6), suggesting the possible presence of multiple Arg-specific peptidases in Pre. intermedia. In addition, the finding that BAU17746 never showed hydrolysis of ArgArg-MCA raised doubt about its aminopeptidase activity, because Arg-specific aminopeptidase should sequentially degrade Arg-Arg-MCA into an arginine and Arg-MCA, and finally, into two arginines and 7-amino-4-methylcoumarin.

An updated BLAST search indicated a $26.6 \%$ identity of amino acid sequence of BAU17746 to that of L. helveticus dipeptidase A (MER0002163), a representative C69.001-subfamily dipeptidase A/PepDA (Table 2). In addition, we found that $T$. forsythia putative dipeptidase (MER0284871) possesses $74.9 \%$ identity to BAU17746, which recorded the highest value except for those from other strains of Pre. intermedia. These findings suggested that even though BAU17746 was suspected to be an aminopeptidase, it might be a dipeptidase belonging to the C69.001, of which Arg-MCA is accepted as a dipeptide.

Since Leu-Leu was reported to be the preferred substrate for L. helveticus dipeptidase A (Dudley et al., 1996; 2012), we examined the dipeptidase activity of BAU17746 using a modified cadmiumninhydrin assay with the substrates Arg-Leu and Arg-Phe. Those results conclusively demonstrated that BAU17746 hydrolyzed these dipeptides, while its inert mutants $(\Delta \mathrm{N} 1-35$ and $\mathrm{C} 15 \mathrm{~A})$ did not (Figure 7). Maximum dipeptidase activity was achieved at $\mathrm{pH} 8.3$ in sodium phosphate buffer and at $\mathrm{pH} 8$ in Tris$\mathrm{HCl}$ buffer (data not shown), identical to the $\mathrm{pH}$ profile for Arg-MCA hydrolysis. Noticeably, dipeptidase activity was higher toward Arg-Leu and Arg-Phe than Leu-Leu, followed by Glu-Glu. Furthermore, hydrolysis of the tripeptide Leu-Leu-Leu was not observed (Figure 7B). The dipeptide Arg-Xaa was much more preferential than Arg-MCA for BAU17746, since the specific activities (20 $\mathrm{nmol} / \mathrm{min} / \mu \mathrm{g}$ ) toward Arg-Leu and Arg-Phe (Figure 7A) were at least 500-fold higher than $V_{\max }(0.041$ $\mathrm{nmol} / \mathrm{min} / \mu \mathrm{g}$ ) for Arg-MCA (Figure $6 \mathrm{E}$ ), presumably due to a non-suitable structure at the MCA at the P1' position. The low $k_{\text {cat }}$ and $k_{\text {cat }} / K_{\mathrm{m}}$ values for Arg-MCA may be related to these findings. Conclusively, BAU17746 does not encode an aminopeptidase, but is a dipeptidase belonging to the C69 dipeptidase A family.

\section{P1-position specificity of C69.001-family dipeptidase A}

C69.001 dipeptidase $\mathrm{A}$ is represented by the $L$. helveticus entity. It was previously reported that $L$. helveticus dipeptidase A shows broad preference, except for Pro, at both the P1 and P1' position residues, and that bulky hydrophobic residues, such as Leu-Leu, Phe-Leu (Dudley et al., 1996; 2012), 
and Met-Leu (Vesanto et al., 1996), were found to be most efficiently hydrolyzed. Hence, the present results raise a question with respect to the P1-position (N-terminal) specificity. To address this issue, substrate specificity L. helveticus dipeptidase A as well as a putative dipeptidase member from the periodontopathic bacterium $T$. forsythia possessing the highest identity (74.9\%) to BAU17746 was examined. Recombinant dipeptidase A from L. helveticus and the putative dipeptidase of $T$. forsythia migrated to 60 and $55 \mathrm{kDa}$, respectively, in accordance with their calculated molecular masses (Figure 8A). Despite a previously reported preference for bulky hydrophobic amino acids, our findings showed L. helveticus dipeptidase A to be preferential for P1 Arg as Pre. intermedia peptidase (Figure 8B). In contrast, the $T$. forsythia dipeptidase was not preferential for the P1-position Arg, but rather for Leu (Figure 8C). As expected, these dipeptidases did not hydrolyze the tripeptide Leu-Leu-Leu or dipeptidyl-MCA substrates (data not shown). Accordingly, these results indicate that the C69.001 dipeptidase $\mathrm{A}$ is comprised of at least two types of dipeptidases, one preferential for dipeptides with the P1-position Arg and the other preferential for those with hydrophobic P1 residues.

\section{P1'-position specificity of C69-family dipeptidase A}

A previous study demonstrated that hydrolysis of Met-Ala (433\%), Leu-Gly (272\%), Phe-Gly (169\%), Ala-Phe (133\%), Arg-Asp (105\%), and Lys-Ala (103\%) was superior to that of Leu-Leu $(100 \%)$ (Vesanto et al., 1996). Hence, we investigated the C-terminal preference of C69.001 dipeptidases toward dipeptides with P1 Arg and P1' Leu, Phe, Met, Ala, Gly, Arg, Lys, and Asp. Among them, Pre. intermedia dipeptidase A most efficiently hydrolyzed Arg-Gly, Arg-Phe, and Arg-Leu, and the other dipeptides were moderately hydrolyzed, except for Arg-Lys (Figure 9A). Arg-Phe was the best substrate for L. helveticus dipeptidase A, with other dipeptides, except for Arg-Lys and Arg-Asp, found to be moderately hydrolyzed. A similar preference regarding Arg-Xaa dipeptides was shown by $T$. forsythia dipeptidase A, except that a lower level of efficacy was observed with Arg-Arg and Arg-Lys (Figure 9B). Importantly, Leu-Leu was again the most superior among the examined substrates as compared to P1 Arg-containing dipeptides for T. forsythia dipeptidase. These results indicate that (i) P1 preference, i.e., Arg or Leu, is altered between the Pre. intermedia and L. helveticus dipeptidase A and T. forsythia entity; (ii) P1' Lys is commonly unfavorable, and Arg and Asp are occasionally acceptable, and (iii) non-charged residues at the P1' position are relatively preferable for the three peptidases. These observations suggest that P1'-position residues are not as strictly selected as compared to P1 position residues. Taken together, we concluded that three dipeptides, Arg-Leu, Arg-Phe, and Arg-Gly, are appropriate substrates for Pre. intermedia and L. helveticus dipeptidase A, and that Leu-Leu is a good substrate for $T$. forsythia dipeptidase.

\section{Discussion}

The present results demonstrated that dominant Arg-MCA hydrolysis shown in Pre. intermedia is mediated by Arg-specific dipeptidase BAU17746 that belongs to the C69-family dipeptidase A. Pre. Intermedia dipeptidase $\mathrm{A}$ is composed of 479 amino acid residues with the essential Cys ${ }^{15}$. In our experiments, it was found to preferentially hydrolyze Arg-Gly, Arg-Phe, and Arg-Leu, and other dipeptides with P1 Arg, except for Arg-Lys, were moderately hydrolyzed.

The P1 Arg specificity of BAU17746 is apparently incompatible with the P1 Leu preference of $L$. helveticus dipeptidase A (Dudley et al., 1996; 2012; Vesanto et al., 1996). However, the present investigation revealed that $L$. helveticus dipeptidase A also exhibits a P1 Arg preference and further indicated that the lack of Arg preference noted in the previous study was due to usage of Arg-Asp, as we found that P1'-position Asp as well as Lys were least preferable for L. helveticus dipeptidase A (Figure 9B). Our results further demonstrated that all molecules annotated as the C69.001 dipeptidase A are not specific for P1 Arg, because T. forsythia dipeptidase A shows a preference for P1 Leu. Hence, this subfamily comprises at least two dipeptidase members with distinct specificities, i.e., Arg and Leu at the P1 position.

Pre. intermedia and T. forsythia each possess one dipeptidase A gene, while L. helveticus possesses 5 genes of the C69.001 subfamily (Rawlings et al., 2012), of which only one (MER0233043/PepDA) has been enzymatically and biochemically characterized (Dudley et al., 1996; Vesanto et al., 1996; this 
study). Based on the present findings showing multiple P1 preferences of the C69.001 subfamily, characterization of other members is a topic of interest.

Sequence-based classification of the C69.001 members into P1 Arg- and Leu-preferential subtypes seems inappropriate, because the sequence identity between altered P1 preferential Pre. intermedia and T. forsythia dipeptidase A is much greater than that between Arg-preferential Pre. intermedia and $L$. helveticus dipeptidase A (Table 2). We previously reported that the alteration in substrate specificity between DPP7 specific for hydrophobic residues and DPP11 for acidic ones is primarily defined by a single amino acid residue composing the active center (Ohara-Nemoto et al., 2011; Rouf et al., 2013). Similarly, we attempted to find an essential amino acid residue to produce P1 Arg or Leu specificity of the dipeptidases, though no such residue in the C69.001 subfamily was found in our examinations to date.

The present study also demonstrated that P1'-position residues of dipeptidase A are not stringent. Gly, Phe, and Leu at the P1' position of dipeptides showed relatively higher potentials, while moderate potentials were shown by the other residues. The ambiguity of a P1' residue in substrates has been previously demonstrated in three-dimensional structure analysis of $P$. gingivalis DPP11, which strictly binds to Asp and Glu residues at the P1 position, though an interaction with the P1'-position residue was found to be relaxed (Bezerra et al., 2017). Results of the present study revealed that Arg-Gly, ArgPhe, and Arg-Leu are the best substrates for Pre. intermedia dipeptidase A (BAU17746), and Arg-Phe the best for L. helveticus dipeptidase A.

Our study revealed the unique N-terminal location of the essential catalytic cysteine residue $\left(\mathrm{Cys}^{15}\right)$ in a mature form of BAU17746. This indicates cleavage of the proenzyme at the Glu ${ }^{14}$-Cys ${ }^{15}$ bond, which apparently occurs via the intramolecular proteolysis within the polypeptide chain of the zymogen. In this respect the BAU17746 zymogenic form exerted endopeptidase activity on itself to release the mature form with the exclusive dipeptidase activity. We should notify that essential cysteine residues of the C69.001 subfamily are located near the N-terminus of the sequences at $2^{\text {nd }}$ to $26^{\text {th }}$ positions from $\mathrm{Met}^{1}$ (Rawlings et al., 2012), which indicates that this subfamily members commonly possess essential cysteines at the $\mathrm{N}$-termini of the mature forms. In fact, we noticed the existence of a higher molecular mass species in addition to the major one of $T$. forsythia dipeptidase, when a large amount of proteins was loaded (data not shown). Furthermore, it has been reported that the N-terminus of purified S. gordonii Arg-aminopeptidase appeared to be modified, because N-terminal sequencing was not successful (Goldstein et al., 2002). However, it is well known that cysteine residue is not easily identified by N-terminal sequencing (Figure 4C), and thus, we suspect that $\mathrm{Cys}^{26}$ is located at the Nterminus in a mature form of $S$. gordonii Arg-aminopeptidase. If so, an essential cysteine of the C69.002 subfamily is also located at the N-terminus.

By comparison with Penicillin V acylase, Class II glutamine amidotransferases, Penicillin G acylase, and proteasome catalytic subunits, Pei and Grishin (2003) previously proposed that L. helveticus dipeptidase A, which used to be classified in MEROPS to peptidases with unknown catalytic type U34, belong to the superfamily of $\mathrm{N}$-terminal nucleophile hydrolases and insisted that the essential residue should be located at the N-terminus beyond the classes of cysteine, serine, and threonine peptidases. The findings on this study truly confirmed their hypothesis.

It should noted that the processing of the $\mathrm{Glu}^{14}-\mathrm{Cys}{ }^{15}$ bond of BAU17746 proenzyme is intramolecularly mediated by an endopeptidase activity of the proenzyme, although the mature BAU17746 is a dipeptidase. Our preliminary data suggest that $\mathrm{Glu}^{14}$ is most suitable for the autoprocessing, and $\mathrm{Asp}^{14}$ is the second-best residue for this process (M.T.S and T.K.N, unpublished observation). However, a dipeptide Glu-Glu is not an appropriate substrate of BAU17746 (Figure 7B). Furthermore, the amino acid sequences of Pre. intermedia and T. forsythia dipeptidase A at the processing site were Pro ${ }^{12}$-Ser-Glu-Cys ${ }^{15}$ (numbering in BAU17746) and that of L. helveticus is Gln ${ }^{3}-$ Ser-Glu-Cys ${ }^{6}$. Therefore, the P1-position specificity of the dipeptidases is distinct from the specificity of the processing site specificity. However, this may be not surprising that some of the members in the $\mathrm{N}$-terminal nucleophilic hydrolase superfamily are not peptidases (Pei and Grishin, 2003).

There are two C69-family members, BAU17746 and BAU18827, in Pre. intermedia. Although we speculated that both may represent dipeptidases with altered specificity, our attempts to detect aminoacyl-MCA hydrolysis as well as dipeptide hydrolysis of BAU18827 have not been successful to date. Similarly, there are two C69-family members in T. forsythia, of which one (MER0284871) is dipeptidase A characterized in this study, while the other (MER0285668) is currently listed as an unassigned member. The latter shows a $43.7 \%$ amino acid identity to BAU18827, indicating their close 
kinship. Furthermore, there is only a single C69-family unassigned peptidase in P. gingivalis (PGN 1103), which has 47.5\% identity to BAU18827. Thus, orthologues of Pre. intermedia BAU18827 are commonly present in T. forsythia and P. gingivalis, as well as other species of the phylum Bacteroidetes, although their activity remains unknown. Our purification data indicated that BAU18827 appeared to be not processed at the $\mathrm{Ala}^{19}{ }^{-\mathrm{Cys}^{20}}$ peptide bond (data not shown), which might be related to no activity of recombinant BAU18827.

Although previous studies have shown that Pre. intermedia produces various kinds of proteases (Suido et al., 1996; Holdeman et al., 1977; Deschner et al., 2003; Potempa et al., 2009; Potempa and Pike, 2009; Yano et al., 2009), little is known about DPPs except for DPP4 (Shibata et al., 2003; Ohara-Nemoto et al., 2017). In the present study, we confirmed expressions of DPP4, DPP5, and DPP7, whereas DPP11 activity was not detected (Figure 1A). In fact, BLAST search results demonstrated that the DPP11 gene is absent in Pre. intermedia. Because the DPP11 and DPP7 genes are distributed in several different anaerobic bacteria, such as those of the phylum Bacteroidetes (Rouf et al., 2013), we speculate that the ancestor of Pre. intermedia also possessed the DPP 11 gene that may have been lost during its evolution. Nevertheless, it is important to note that even though deletion of only a single DPP gene may significantly reduce efficiency for complete metabolism of polypeptides into dipeptides, that may be not have a significant effect on growth of this species, because Pre. intermedia can utilize free amino acids as well as dipeptides, in contrast to $P$. gingivalis, which shows dominant dipeptide utilization.

\section{Materials and methods}

\section{Materials}

pQE60 was purchased from Qiagen Inc. (Chatsworth, CA). pGEX4T-1, a Superdex 200 Increase 10/300 GL column, glutathione-Sepahrose 4B, low-molecular-weight markers, and full-range rainbow molecular weight markers were obtained from GE Healthcare (Buchinghamshire, England). Restriction enzymes and DNA-modifying enzymes came from Takara Bio (Tokyo, Japan) and New England Biolabs (Ipswich, MA), while KOD-Plus-Neo DNA polymerase came from Toyobo (Tokyo, Japan). Aminoacyl- and peptidyl-methylcoumaryl-7-amide (MCA) were obtained from the Peptide Institute (Osaka, Japan), Arg-Leu, Arg-Phe, Leu-Leu, and Glu-Glu from Bachem (Bubendorf, Switzerland), and Leu-Leu-Leu from Sigma-Aldrich Japan (Tokyo, Japan). Phe-Met-MCA was synthesized by Scrum (Tokyo, Japan), while Arg-Arg, Arg-Lys, Arg-Met, Arg-Ala, Arg-Asp, and Arg-Gly were synthesized by Biologica Co. (Nagoya, Japan). A ninhydrin reagent was obtained from Fuji Film-Wako Pure Chemicals (Osaka, Japan).

\section{Bacterial cells}

Pre. intermedia OMA14 was isolated from the periodontal pocket of a Japanese patient with periodontitis (Fukushima, 1992). Pre. intermedia OMA14 was selected as the strain can be manipulated for gene transfer, after which the genome project was completed (Naito et al., 2016). Bacteria were grown in anaerobic bacterial culture medium broth (Eiken Chemical Co., Ltd, Tokyo Japan) at $37{ }^{\circ} \mathrm{C}$ under an anaerobic condition. In an early stationary phase, bacterial culture was centrifuged at $9000 \mathrm{xg}$ for $15 \mathrm{~min}$ at $4^{\circ} \mathrm{C}$, and the supernatant filtrated with a $0.45-\mu \mathrm{m}$ filter was saved as culture supernatant at $-80^{\circ} \mathrm{C}$ until use. Bacterial cells were washed with ice-cold phosphate buffered

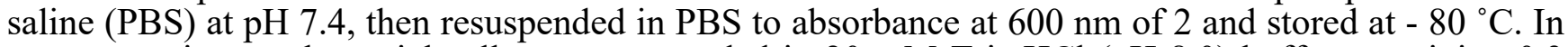
some experiments, bacterial cells were suspended in $20 \mathrm{mM}$ Tris- $\mathrm{HCl}(\mathrm{pH} 8.0)$ buffer containing 0.3 $\mathrm{mg} / \mathrm{ml}$ of lysozyme, $0.1 \mathrm{M} \mathrm{NaCl}, 10 \mu \mathrm{g} / \mathrm{ml}$ of leupeptin, and $3 \mathrm{mM}$ dithiothreitol. After two times of freezing and thawing, the cytosol-periplasm fraction was obtained by centrifugation at 20,400 $\mathrm{x} g$ for 30 $\min$ at $4{ }^{\circ} \mathrm{C}$.

\section{Construction of plasmids}

Pre. intermedia OMA14, L. helveticus ATCC 15009, and Tannerella forsythia ATCC 25611 genomic DNA samples were prepared as previously reported (Ikeda et al., 2004). L. helveticus ATCC 15009 
was obtained from RIKEN BRC JCM (Tsukuba, Japan). A DNA fragment of BAU17746 located at the 1238 position of the first chromosome of Pre. intermedia OMA14 (locus tag PIOMA14_I_1238) (Naito et al., 2016) was amplified by PCR using KOD-Plus-Neo with genomic DNA and an appropriate set of primers (5BAU17746M1Bam, 3BAU17746A479Bam) (Table 1). The PCR fragment was digested by BamHI, then cloned into the BamHI site of pQE60 and GEX4T-1, as previously described (Ohara-Nemoto et al., 2011), with the resulting plasmid designated as pQE60-BAU17746 and pGEX4T-1-BAU17746, respectively. Similarly, the DNA fragment of BAU18827 located at the 322 position of the second chromosome (PIOMA14_II_0322), genes for L. helveticus dipeptidase A (MER0002163, KEGG entry: K08659, Uniprot accession: Q48558), and T. forsythia putative dipeptidase (MER0284871) were cloned into pQE60, and designated as pQE60-BAU18827, pQE60LhpepDA, and pQE60TfpepD, respectively. pQE60 plasmids encoding the N-terminal 35-residue deleted form of BAU17746 (pQE60-BAU17746 $\mathrm{N} 1-35$ ) and an amino acid substitution from Cys ${ }^{15}$ to Ala (pQE60-BAU17746C15A and pGEX4T-1-BAU17746C15A) were prepared by PCR with pQ60BAU17746 and pGEXT4T-1-BAU17746, respectively, using appropriate primer sets (Table 1), as previously described (Ohara-Nemoto et al., 2011).

\section{Expression and purification of recombinant proteins}

Escherichia coli XL-1 Blue transformed with the expression plasmids were cultured in Luria-Bertani broth containing $75 \mu \mathrm{g} / \mathrm{ml}$ of ampicillin. Following an overnight culture, proteins were expressed using $0.2 \mathrm{mM}$ isopropyl-thiogalactopyranoside at $30{ }^{\circ} \mathrm{C}$ for $4 \mathrm{~h}$. After harvesting and lysing, the bacterial cell lysate was obtained by centrifugation at $15,000 \mathrm{xg}$ for $40 \mathrm{~min}$ at $4{ }^{\circ} \mathrm{C}$ and recombinant proteins were purified by Talon affinity chromatography or glutathione-Sepharose $4 \mathrm{~B}$, as previously reported (OharaNemoto et al., 2011; Nemoto et al., 1994). Proteins were stored at - $80{ }^{\circ} \mathrm{C}$ until use.

\section{Measurement of peptidase activity with fluorogenic substrates}

Peptidase activity was determined using aminoacyl- and peptidyl-MCA, as previously reported (OharaNemoto et al., 2011; 2014). Briefly, an enzyme reaction was started by addition of recombinant proteins $(100-200 \mathrm{ng})$ or a cell suspension $\left(10 \mu \mathrm{l}\right.$ of $\left.\mathrm{A}_{600}=2.0\right)$ to a reaction mixture $(200 \mu \mathrm{l})$ composed of $50 \mathrm{mM}$ sodium phosphate buffer ( $\mathrm{pH} 7.7), 5 \mathrm{mM}$ EDTA, $60 \mathrm{mM}$ dithiothreitol, and 20 $\mu \mathrm{M}$ aminoacyl- or peptidyl-MCA. After $30 \mathrm{~min}$ at $37^{\circ} \mathrm{C}$, fluorescence intensity was measured with excitation at $380 \mathrm{~nm}$ and emission at $460 \mathrm{~nm}$. For some experiments, $\mathrm{pH}$ was varied by use of $50 \mathrm{mM}$ sodium phosphate $(\mathrm{pH} 5-8)$ or Tris- $\mathrm{HCl}(\mathrm{pH} 7-10)$, and the concentration of dithiothreitol was also varied from $0-300 \mathrm{mM}$.

To determine enzymatic parameters, recombinant BAU17746 was incubated with $0-10 \mu \mathrm{M}$ ArgMCA. Data were analyzed using a nonlinear regression curve fitted to the Michaelis-Menten equation with the GraphPad Prism software package (GraphPad Software Inc., La Jolla, CA). Values were calculated from 4 independent measurements.

\section{Dipeptidase activity determination by ninhydrin assay}

Dipeptidase activity was determined with $0.3 \mathrm{mM}$ di- and tripeptides in a reaction mixture $(200 \mu \mathrm{l})$ using a modified cadmium-ninhydrin method (Doi et al.,1981). BAU17746 and T. forsythia dipeptidase were incubated in a reaction mixture composed of $50 \mathrm{mM}$ sodium phosphate $(\mathrm{pH} 8.3)$ and $10 \mathrm{mM}$ dithiothreitol at $37{ }^{\circ} \mathrm{C}$, while L. helveticus dipeptidase A was incubated in $50 \mathrm{mM}$ MES (pH 6.0) at 55 ${ }^{\circ} \mathrm{C}$ with $10 \mathrm{mM}$ dithiothreitol. After $30 \mathrm{~min}, 400 \mu \mathrm{l}$ of cadmium-ninhydrin solution was added and the mixture was heated at $80{ }^{\circ} \mathrm{C}$ for $10 \mathrm{~min}$. After cooling, absorbance at $508 \mathrm{~nm}$ was determined. Leucine was used as the standard for the ninhydrin reaction.

\section{Size exclusion HPLC}

Recombinant protein or bacterial lysate was subjected to size exclusion HPLC using an ÄKTA explorer 10S (GE Healthcare) with a Superdex 200 Increase 10/300 GL column $(1.5 \times 30 \mathrm{~cm})$ equilibrated with $20 \mathrm{mM}$ Tris- $\mathrm{HCl}(\mathrm{pH} 8.0)$ and $50 \mathrm{mM} \mathrm{NaCl}$. Samples were eluted at a rate of $0.5 \mathrm{ml} / \mathrm{min}$ at room temperature, with $0.5-\mathrm{ml}$ fractions collected. Aliquots of the fractions were subjected to a peptidase 
assay with Arg-MCA and SDS-PAGE.

\section{SDS-PAGE, immunoblotting, and N-terminal sequencing}

Purified proteins were separated by PAGE in the presence of $0.1 \%(\mathrm{w} / \mathrm{v})$ of SDS with a polyacrylamide concentration of $10 \%(\mathrm{w} / \mathrm{v})$, and then stained with Coomassie brilliant blue R250 (CBB or transferred to a polyvinylidene difluoride membrane (Merck-Millipore, Darmstadt, Germany). Immunoblotting was performed by using the anti-GST antiserum ( $2 \times 10^{3}$-fold dilution), and blots were visualized with alkaline phosphatase-conjugated anti-rabbit $\operatorname{Ig}(\mathrm{G}+\mathrm{A}+\mathrm{M})$ using 5bromo-4-chloro-3-indolyl phosphate and nitro blue tetrazolium (Promega). An anti-GST antiserum was developed with recombinant GST as an antigen in rabbits with the method reported previously (Ohara-Nemoto et al., 2011; 2014). For the N-terminal sequencing, separated proteins were transferred to a Sequi-Blot membrane (Bio-Rad Laboratories, Hercules, CA), stained with CBB. The $\mathrm{N}$-terminal sequences of CBB-stained bands were determined in Protein Research Institute (Osaka, Japan).

\section{Protein concentration}

Protein concentration was determined with a protein assay method (Bio-Rad), with bovine serum albumin used as the standard.

\section{Acknowledgments}

This study was supported by JSPS KAKENHI grants (JP19K10045 to T.K.N. and JP19K10071 to Y.O.-N.). M.T.S. is a graduate student supported by a Japanese Government (MEXT) Scholarship. 


\section{References}

Baumgartner, J.C., Watkins, B.J., Bae, K.S., and Xia, T. (1999). Association of black-pigmented bacteria with endodontic infections, J. Endod. 25, 413-415.

Bezerra, G.A., Ohara-Nemoto, Y., Cornaciu, I., Fedosyuk, S., Hoffmann, G., Round, A., Márquez, J.A., Nemoto, T.K., and Djinović-Carugo, K. (2017). Bacterial protease uses distinct thermodynamic signatures for substrate recognition. Sci. Rep. 7, 2848 doi: 10.1038/s41598-017-03220-y.

Chen, Z., Potempa, J., Polanowski, A., Wikstrom, M., and Travis, J. (1992). Purification and characterization of a 50-kDa cysteine proteinase (gingipain) from Porphyromonas gingivalis. J. Biol. Chem. 267,18896-188901.

Deng, Z.L., Szafrański, S.P., Jarek, M., Bhuju, S., and Wagner-Döbler, I. (2017). Dysbiosis in chronic periodontitis: key microbial players and interactions with the human host, Sci. Rep. 7, 3703.

Deschner, J., Singhal, A., Long, P., Liu, C.C., Piesco, N., and Agarwal, S. (2003). Cleavage of CD14 and LBP by a protease from Prevotella intermedia, Arch. Microbiol. 179, 430-436.

Doi, E., Shibata, D., and Matoba, T. (1981). Modified colorometric ninhydrin methods for peptidase assay, Anal. Biochem. 118, 173-184.

Dudley, E.G., Husgen, A.C., He, W., and Steele, J.L. (1996). Sequencing, Distribution, and Inactivation of the Dipeptidase A Gene (pepDA) from Lactobacillus helveticus CNRZ32, J. Bacteriol. 178, 701-704.

Dudley, E.G. and Steele, J.L. (2012). Dipeptidase DA. In Handbook of Proteolytic Enzymes, 3 edn (Rawlings, N.D. and Salvesen, G. S. eds), p3657-p3659, Elsevier, Amsterdam.

Eiring, P., Waller, K., Widmann, A., and Werner, H. (1998). Fibronectin and laminin binding of urogenital and oral prevotella species, Zentralbl, Bakteriol. 288, 361-372.

Friedrich, V., Janesch, B., Windwarder, M., Maresch, D., Braun, M.L., Megson, Z. A., Vinogradov, E., Goneau, M.F., Sharma, A., Altmann, F., Messner, P., Schoenhofen, I. C., and Schäffer, C. (2017). Tannerella forsythia strains display different cell-surface nonulosonic acids: biosynthetic pathway characterization and first insight into biological implications. Glycobiology 27, 342-357. doi: 10.1093/glycob/cww129.

Fukushima, H., Yamamoto, K., Hirohata, K., Sagawa, H., Leung, K.P., and Walker, C.B. (1990). Localization and identification of root canal bacteria in clinically asymptomatic periapical pathosis, J. Endod. 16, 534-538.

Fukushima, H. (1992). Phenotypic characteristics and DNA relatedness in Prevotella intermedia and similar organisms, Oral Microbiol. Immunol. 7, 60-64.

Goldstein, J.M., Nelson, D., Kordula, T., Mayo, J.A., and Travis, J. (2002). Extracellular Arginine Aminopeptidase from Streptococcus gordonii FSS2, Infect. Immun. 70, 836-843.

Gomes, B.P., Drucker, D.B., and Lilley, J.D. (1994). Associations of specific bacteria with some endodontic signs and symptoms, Int. Endod. J. 27, 291-298.

Gomes, B.P., Lilley, J.D., and Drucker, D.B. (1996). Associations of endodontic symptoms and signs with particular combinations of specific bacteria, Int. Endod. J. 29, 69-75.

Hayashi, H., Shibata, K., Sakamoto, M., Tomita, S., and Benno, Y. (2007). Prevotella copri sp. nov. and Prevotella stercorea sp. nov., isolated from human feces, Int. J. Syst. Evol. Microbiol. 57, 941-946.

Holdeman, L.V., Cato, E.P., and Moore, W.E (1977). Anaerobic laboratory manual. 4, Blacksburg, V.A.: Virginia Polytechnic Institute and State University.

Ikeda, Y., Ohara-Nemoto, Y., Kimura, S., Ishibashi, K., and Kikuchi, K. (2004). PCR-based identification of Staphylococcus epidermidis targeting gseA encoding the glutamic-acid-specific protease, Can. J. Microbiol. 50, 493-498.

Jacinto, R.C., Gomes, B.P., Ferraz, C.C., Zaia, A.A., and Filho, F.J. (2003). Microbiological analysis of infected root canals from symptomatic and asymptomatic teeth with periapical periodontitis and the antimicrobial susceptibility of some isolated anaerobic bacteria, Oral Microbiol. Immunol. 18, 285-292.

Loesche, W.J., Syed, S.A., Laughon, B.E., and Stoll, J. (1982) The bacteriology of acute necrotizing ulcerative gingivitis, J. Periodontol. 53, 223-230.

Naito, M., Ogura, Y., Itoh, T., Shoji, M., Okamoto, M., Hayashi, T., and Nakayama, K. (2016). The complete genome sequencing of Prevotella intermedia strain OMA14 and a subsequent fine-scale, intra-species genomic comparison reveals an unusual amplification of conjugative and mobile 
transposons and identify a novel Prevotella-lineage-specific repeat, DNA Res. 23, 11-19.

Nemoto, T., Ohara-Nemoto, Y., Shimazaki, S., and Ota, M., (1994). Dimerization characteristics of the DNA- and steroid-binding domains of the androgen receptor, J. Steroid Biochem. 50 225-233.

Nemoto, T.K. and Ohara-Nemoto, Y. (2016). Exopeptidases and gingipains in Porphyromonas gingivalis as prerequisites for its amino acid metabolism, Jpn. Dental Sci. Rev. 52, 22-29.

Nemoto, T.K., Ohara- Nemoto, Y., Bezerra, G.A., Shimoyama, Y., and Kimura, S. (2016). A Porphyromonas gingivalis periplasmic novel exopeptidase, acylpeptidyl oligopeptidase, releases N-acylated di- and tri-peptides from oligopeptides, J. Biol. Chem. 291, 5913-5925.

Nemoto, T.K., Ono, T., and Ohara-Nemoto, Y. (2018). Establishment of potent and specific synthetic substrate for dipeptidyl-peptidase 7, Anal. Biochem. 548, 78-81.

Offenbacher, S., Lieff, S., Boggess, K.A., Murtha, A.P., Madianos, P. N., Champagne, C.M., McKaig, R.G., Jared, H.L., Mauriello, S.M., Auten Jr, R.L., Herbert, W.N., and Beck, J.D. (2001). Maternal periodontitis and prematurity. Part I: obstetric outcome of prematurity and growth restriction, Ann. Periodontol. 6, 164-174.

Ohara-Nemoto, Y., Shimoyama, Y., Kimura, S., Kon, A., Haraga, H., Ono, T., and Nemoto, T. K. (2011). Asp- and Glu-specific novel dipeptidyl peptidase 11 of Porphyromonas gingivalis ensures utilization of proteinaceous energy sources, J. Biol. Chem. 286, 38115-38127.

Ohara-Nemoto, Y., Rouf, S.M., Naito, M., Yanase, A., Tetsuo, F., Ono, T., Kobayakawa, T., Shimoyama, Y., Kimura, S., Nakayama, K., Saiki, K., Konishi, K., and Nemoto, T.K. (2014). Identification and characterization of prokaryotic dipeptidyl-peptidase 5 from Porphyromonas gingivalis, J. Biol. Chem. 289, 5436-5448.

Ohara-Nemoto, Y., Nakasato, M., Shimoyama, Y., Baba, T.T., Kobayakawa, T., Ono, T., Yaegashi, T., Kimura, S., and Nemoto, T.K. (2017). Degradation of incretins and modulation of blood glucose levels by periodontopathic bacterial dipeptidyl peptidase 4, Infect. Immun. 85 pii: e00277-17 doi: 10.1128/IAI.00277-17.

Ohara-Nemoto, Y., Shimoyama, Y., Nakasato, N., Nishimata, H., Ishikawa, T., Sasaki, M., Kimura, S., and Nemoto, T.K. (2018). Distribution of dipeptidyl peptidase (DPP) 4, DPP5, DPP7, and DPP11 in human oral microbiota-potent biomarkers indicating presence of periodontopathic bacteria, FEMS Microbiol. Lett. 365 doi: 10.1093/femsle/fny221.

Pavloff, N., Potempa, J., Pike, R.N., Prochazka, V., Kiefer, M.C., Travis, J., and Barr, P.J. (1995) Molecular cloning and structural characterization of the Arg-gingipain proteinase of Porphyromonas gingivalis. Biosynthesis as a proteinase-adhesin polyprotein.

J. Biol. Chem. 270, 1007-1010.

Pavloff, N., Pemberton, P.A., Potempa, J., Chen, W.C., Pike, R.N., Prochazka, V., Kiefer, M.C., Travis, J., and Barr P.J. (1997) Molecular cloning and characterization of Porphyromonas gingivalis lysine-specific gingipain. A new member of an emerging family of pathogenic bacterial cysteine proteinases. J Biol Chem. 272 1595-1600.

Pei, J. and Grishin, N.V. (2003). Peptidase family U34 belongs to the superfamily of N-terminal nucleophile hydrolyases, Potein Sci. 12, 1131-1135.

Pike, R., McGraw, W., Potempa, J., and Travis, J. (1994). Lysine- and arginine-specific proteinases from Porphyromonas gingivalis. Isolation, characterization, and evidence for the existence of complexes with hemagglutinins. J. Biol. Chem. 269 406-411.

Potempa, J., Banbula, A., and Travis, J. (2000). Role of bacterial proteinases in matrix destruction and modulation of host responses, Periodontol. 2000 24, 153-192.

Potempa, M., Potempa, J., Kantyka, T., Nguyen, K. A., Wawrzonek, K., Manandhar, S.P., Popadiak, $\underline{K}$., Riesbeck, $\underline{K}$., Eick, $\underline{\mathrm{S}}$, and Blom, A.M. (2009). Interpain A, a cysteine proteinase from Prevotella intermedia, inhibits complement by degrading complement factor C3, PLoS Pathog. 5. e1000316. doi: 10.1371/journal.ppat.1000316.

Potempa, J. and Pike, R.N. (2009). Corruption of innate immunity by bacterial proteases, J. Innate Immun. 1, 70-87.

Raber-Durlacher, J.E., Van Steenbergen, T.J., Van der Velden, U., De Graaff, J., and Abraham-Inpijn, L. (1994). Experimental gingivitis during pregnancy and post-partum: clinical, endocrinological, and microbiological aspects, J. Clin. Periodontol. 21,549-558.

Rams, T.E. and van Winkelhoff, A.J. (2017). Introduction to clinical microbiology for the general dentist, Dent. Clin. North Am. 61, 179-197. 
Rawlings, N.D., Barrett, A.J., and Bateman, A. (2012). MEROPS: the database of proteolytic enzymes, their substrates and inhibitors, Nucleic Acids Res. 40 D343-D350 doi: 10.1093/nar/gkr987.

Rouf, S.M.A., Ohara-Nemoto, Y., Hoshino, T., Fujiwara, T., Ono, T., and Nemoto, T.K. (2013). Discrimination based on Gly and Arg/Ser at position 673 between dipeptidyl-peptidase (DPP) 7 and DPP11, widely distributed DPPs in pathogenic and environmental gram-negative bacteria, Biochimie 95, 824-832.

Scannapieco, F.A., Bush, R.B., and Paju, S. (2003). Associations between periodontal disease and risk for atherosclerosis, cardiovascular disease, and stroke, A systematic review, Ann. Periodontol. 8, $38-53$.

Scott, C.F., Whitaker, E.J., Hammond, B.F., and Colman, R.W. (1993). Purification and characterization of a potent $70-\mathrm{kDa}$ thiol lysyl-proteinase (Lys-gingivain) from Porphyromonas gingivalis that cleaves kininogens and fibrinogen, J. Biol. Chem. 268, 7935-7942.

Shah, H.N. and Williams, R.A.D. (1987). Utilization of glucose and amino acids by Bacteroides intermedius ad Bacteroides gingivalis, Curr. Microbiol. 15, 241-246.

Shibata, Y., Miwa, Y., Hirai, K., and Fujimura, S. (2003). Purification and partial characterization of a dipeptidyl peptidase from Prevotella intermedia, Oral Microbiol. Immunol. 18, 196-198.

Suido, H., Nakamura, M., Mashimo, P.A., Zambon, J.J., and Genco, R.J. (1986). Arylaminopeptidase activities of oral bacteria. J. Dent. Res. 65, 1336-1340.

Takahashi, N., and Sato, T. (2001). Preferential utilization of dipeptides by Porphyromonas gingivalis, J. Dent. Res. 80, 1425-1429.

Vesanto, E., Peltoniemi, K., Purtsi, T., and Steele, J.L. (1996). Molecular characterization, overexpression and purification of a novel dipeptidase from Lactobacillus helveticus, Appl. Microbiol. Biotech. 45, 638-645.

Way, G., Morrice, N., Smythe, C., and O'Sullivan, A.J. (2002). Purification and identification of secernin, a novel cytosolic protein that regulates exocytosis in mast cells, Mol. Cell. Biol. 13, 3344-3354.

Yanagisawa, M., Kuriyama, T., Williams, D.W., Nakagawa, K., and Karasawa, T. (2006). Proteinase activity of prevotella species associated with oral purulent infection, Curr. Microbiol. 52, 375-378.

Yano, T., Fukamachi, H., Yamamoto, M., and Igarashi, T. (2009). Characterization of L-cysteine desulfhydrase from Prevotella intermedia, Oral Microbiol. Immunol. 24, 485-492. 
Table 1 Primers used for expression and in vitro mutagenesis.

\begin{tabular}{|c|c|c|c|}
\hline Peptidase & $\begin{array}{l}\text { Original } \\
\text { plasmid }\end{array}$ & Primers & Sequence $\left(5^{\prime}-3^{\prime}\right)$ \\
\hline \multirow[t]{2}{*}{ BAU17746 } & pQE60 & 5BAU188277M1Bam & ACAAATGGATCCATGAAAGAAAATAAAGTT \\
\hline & & 3BAU188277A479Bam & CGGCAGGGATCCTGCGCCGTGGAAAAGATA \\
\hline \multirow[t]{2}{*}{ BAU18827 } & pQE60 & 5BAU18827M1Bam & AATTATGGATCCATGAAGAAACTACTTTTA \\
\hline & & 3BAU18827E546Bam & TTTAAGGGATCCTTCTGCAGGAACTTCAAA \\
\hline \multirow[t]{2}{*}{ BAU17746C15A } & pQE60 & 5BAU17746C15A & GCAACCACGATGATTGTGGGACAGGAAATG \\
\hline & & 3BAU17746E14 & TTCTGATGGTAAATTGCTTACCAAAAC \\
\hline \multirow[t]{2}{*}{ BAU17746 $\Delta 1-35$} & pQE60 & 5BAU17746E36Bam & GTGGCAGGATCCGAAGACTGGGACGCCATG \\
\hline & & 3BAU17746A479Bam & CGGCAGGGATCCTGCGCCGTGGAAAAGATA \\
\hline \multirow[t]{2}{*}{ GST-BAU17746 } & pGEXT4T-1 & 5BAU188277M1Bam & ACAAATGGATCCATGAAAGAAAATAAAGTT \\
\hline & & 3BAU188277A479Bam & CGGCAGGGATCCTGCGCCGTGGAAAAGATA \\
\hline \multirow[t]{2}{*}{ GST-BAU17746C15A } & pQEX4T-1 & 5BAU17746C15A & GCAACCACGATGATTGTGGGACAGGAAATG \\
\hline & & 3BAU17746E14 & TTCTGATGGTAAATTGCTTACCAAAAC \\
\hline \multirow[t]{2}{*}{ Lh dipeptidase A } & pQE60 & 5LhDipepM1 & ATGAAACAAACAGAATGTACTACTATCTT \\
\hline & & 3LhDipepD474 & GTCGAGCAAGTCGTACTTCA \\
\hline \multirow[t]{2}{*}{ Tf dipeptidase A } & pQE60 & 5TFDipepAM1 & TTTTGGATCCATGAATAGTAAAAAGATTAA \\
\hline & & 3TfDipepAA481 & GCTATGGGATCCCGCTCCGGCAAAGC \\
\hline
\end{tabular}

Restriction sites are underlined and mutated nucleotides are written in italics. 
Table 2 Peptidases expressed and extensively discussed in this study.

\begin{tabular}{|c|c|c|c|c|c|c|c|c|c|}
\hline \multirow{2}{*}{$\begin{array}{l}\text { Species and } \\
\text { Strain }\end{array}$} & \multirow[t]{2}{*}{ Genome } & \multirow[t]{2}{*}{ Locus tag } & \multirow[t]{2}{*}{ Protein } & \multirow[t]{2}{*}{ Family $^{\mathrm{a}}$} & \multirow[t]{2}{*}{ Reference } & \multicolumn{4}{|c|}{ Amino acid identity (\%) } \\
\hline & & & & & & $\begin{array}{l}\text { PIOMA14_II } \\
0322\end{array}$ & $\begin{array}{l}\text { NCTC9124_ } \\
00164\end{array}$ & Ihe_1838 & BFO_RS06995 \\
\hline \multirow[t]{2}{*}{$\begin{array}{l}\text { Pre. intermedia } \\
\text { OMA14 }\end{array}$} & AP014597 & $\begin{array}{l}\text { PIOMA14 } \\
\text { I__1238 }\end{array}$ & $\begin{array}{l}\text { BAU17746/ } \\
\text { Dipeptidase/ C69 }\end{array}$ & C69.001 & $\begin{array}{l}\text { Naito et al., } \\
2016\end{array}$ & 13.4 & 21.5 & 26.6 & 74.9 \\
\hline & AP014598 & $\begin{array}{l}\text { PIOMA14 } \\
\text { _ II_0322 }\end{array}$ & $\begin{array}{l}\text { BAU18827/ } \\
\text { Dipeptidase/ C69 }\end{array}$ & $\begin{array}{l}\text { C69 } \\
\text { unassigned }\end{array}$ & $\begin{array}{l}\text { Naito et al., } \\
2016\end{array}$ & 100 & 14.7 & 12.0 & 12.9 \\
\hline $\begin{array}{l}\text { S. gordonii } \\
\text { NCTC9124 }\end{array}$ & LR594041 & $\begin{array}{l}\text { NCTC912 } \\
4 \_00164\end{array}$ & $\begin{array}{l}\text { Arg- } \\
\text { aminopeptidase } \\
(\mathrm{RAP}) / \mathrm{abpB}\end{array}$ & C69.002 & $\begin{array}{l}\text { Golstein et al., } \\
2002\end{array}$ & & 100 & 18.4 & 20.2 \\
\hline $\begin{array}{l}\text { L. helveticus } \\
\text { CNRZ32 }\end{array}$ & СР002081 & lhe_1838 & $\begin{array}{l}\text { Peptidase DA/ } \\
\text { PepDA }\end{array}$ & C69.001 & $\begin{array}{l}\text { Dudley et al., } \\
\text { 1996; Vesanto } \\
\text { et al., } 1996\end{array}$ & & & 100 & 24.5 \\
\hline T. forsythia $92 \mathrm{~A} 2$ & СР003191 & $\begin{array}{l}\mathrm{BFO}_{-} \\
\mathrm{RS} 06995\end{array}$ & C69 & C69.001 & $\begin{array}{l}\text { Friedrich et al., } \\
2017\end{array}$ & & & & 100 \\
\hline
\end{tabular}

${ }^{\mathrm{a}}$ Classification by MEROPS 
Table 3 Effects of peptidase inhibitors and activators on Arg-MCA hydrolysis of Pre. intermedia cells and recombinant BAU17746.

\begin{tabular}{cccc}
\hline Reagent & Concentration & Cells (\%) & BAU17746 (\%) \\
\hline- & - & 100.0 & 100.0 \\
Dithiothreitol & $10 \mathrm{mM}$ & 1196.1 & 4080.6 \\
& $30 \mathrm{mM}$ & 1520.9 & 5690.9 \\
2-Mercaptoethanol & $10 \mathrm{mM}$ & 133.9 & 309.8 \\
& $30 \mathrm{mM}$ & 368.4 & 1832.1 \\
Iodoacetic acid & $5 \mathrm{mM}$ & 0 & 1.93 \\
TLCK & $50 \mu \mathrm{M}$ & 46.7 & 52.9 \\
TPCK & $85 \mu \mathrm{M}$ & 79.1 & 116.7 \\
E-64 & $3 \mu \mathrm{M}$ & 83.8 & 94.6 \\
Pefabloc & $4 \mathrm{mM}$ & 46.9 & 64.3 \\
Leupeptin & $10 \mu \mathrm{M}$ & 38.4 & 84.03 \\
PMSF & $1 \mathrm{mM}$ & 112.5 & 27.04 \\
EDTA & $1 \mathrm{mM}$ & 196.6 & 152.4 \\
EGTA & $1 \mathrm{mM}$ & 225.4 & 157.5 \\
\hline
\end{tabular}

One hundred activities of Pre. intermedia cells and recombinant protein without any additional reagents were set to $100 \%$. 
A

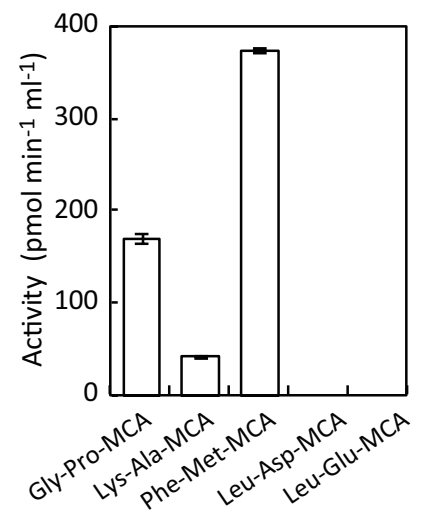

B

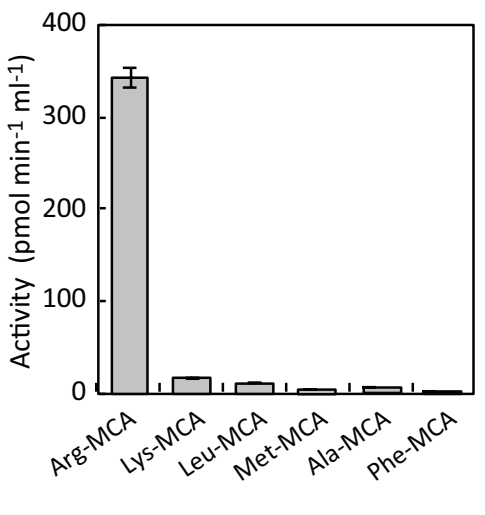

C

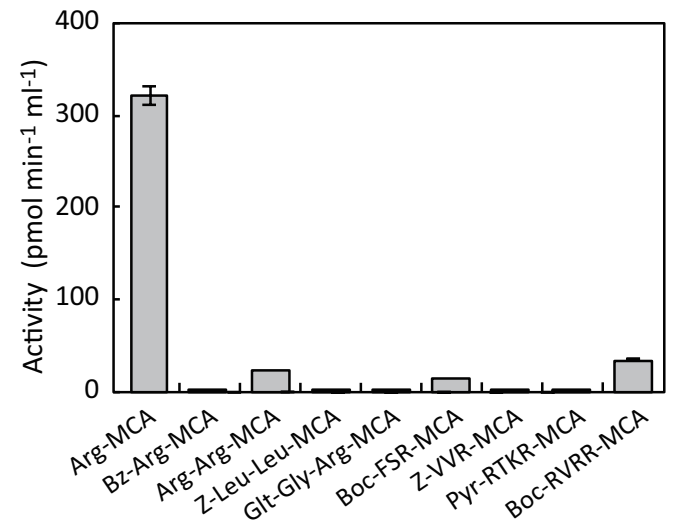

Figure 1 Exopeptidase activities of Pre. intermedia.

(A) Dipeptidyl-peptidase, (B) aminopeptidase, and (C) arginine-specific peptidase activities of cells were determined with MCA substrates. Pre. intermedia cell suspensions $(10 \mu \mathrm{l})$ with $\mathrm{A}_{600} \mathrm{~nm}$ $=2$ were used and the activity is presented per $\mathrm{ml}$ of cells. Values are shown as the mean \pm S.D. $(\mathrm{n}=3)$.

A

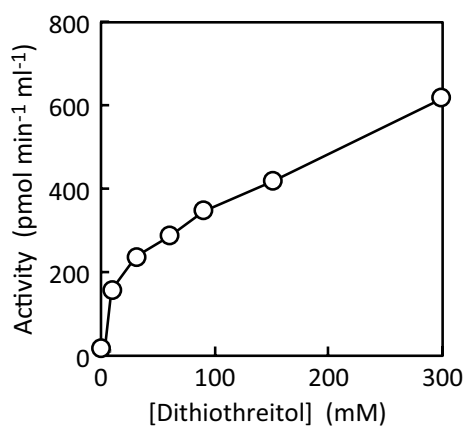

B

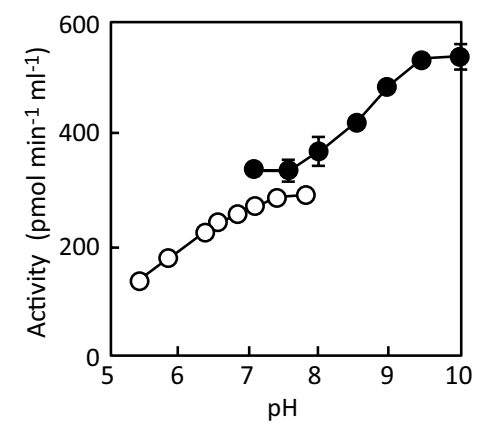

C

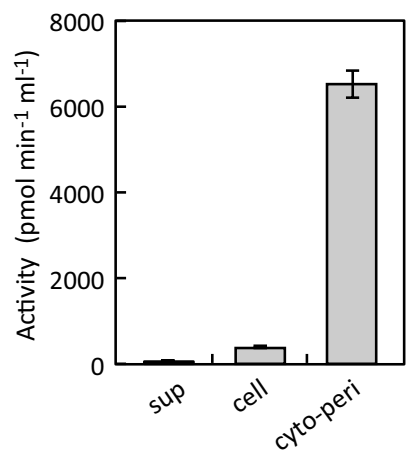

Figure 2 Effects of dithiothreitol, $\mathrm{pH}$ profile, and subcellular localization of Arg-MCA hydrolyzing activity.

(A) Arg-MCA-hydrolyzing activity of Pre. intermedia cells was determined in the presence of 0 - $300 \mathrm{mM}$ dithiothreitol. (B) Arg-MCA-hydrolyzing activity of the cells was determined at $\mathrm{pH} 5$ - 10 in sodium phosphate (open circle) and Tris-HCl (closed circle) buffers. (C) Arg-MCAhydrolyzing activity was determined using culture supernatant (sup), cell suspension (cell), and cytosol-periplasm fraction (cyto-peri) samples. Values are shown as the mean \pm S.D. $(n=3)$. 


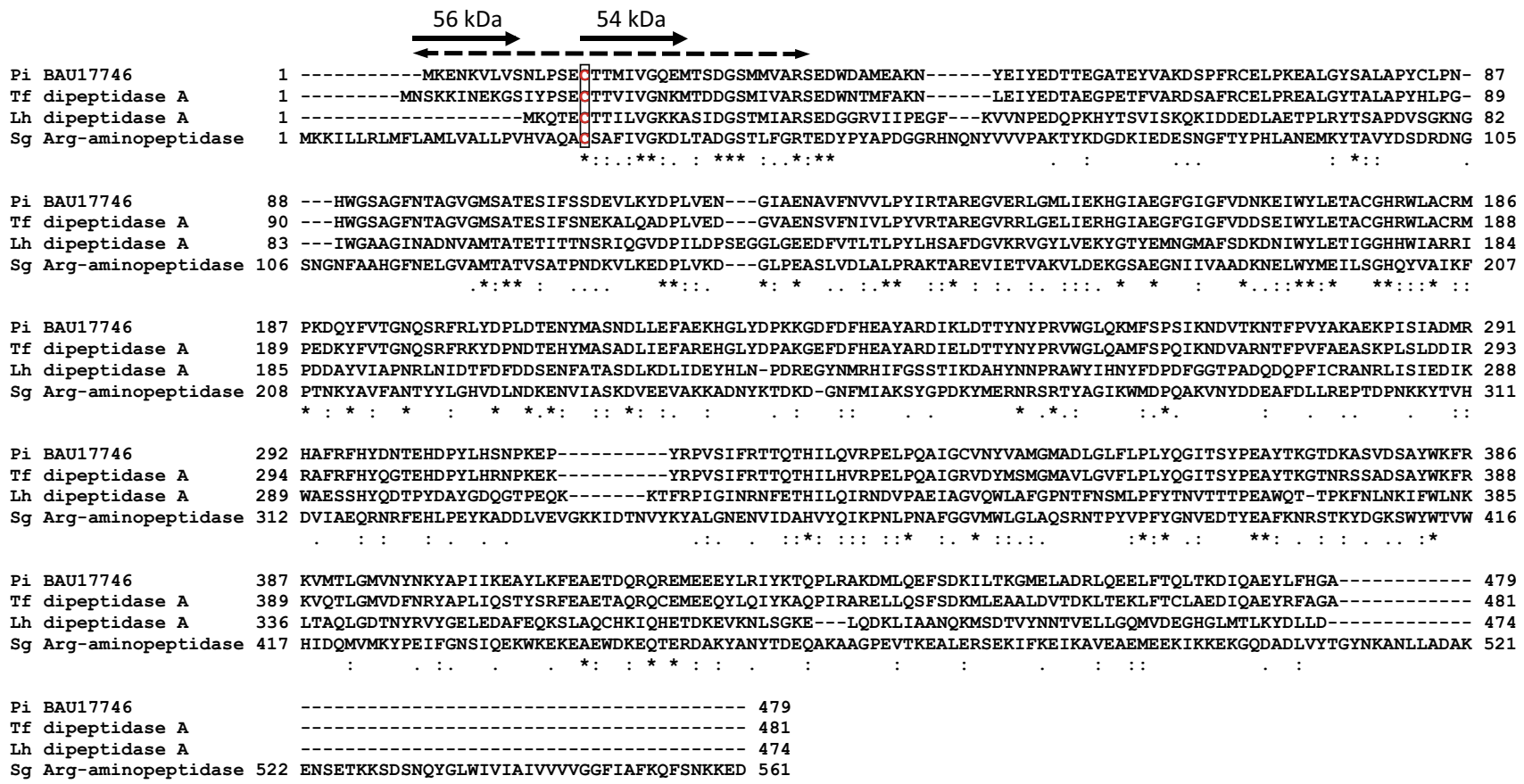

Figure 3 Alignment of amino acid sequences of Pre. intermedia BAU17746, T. forsythia putative dipeptidase, L. helveticus dipeptidase A, and S. gordonii Arg-aminopeptidase.

Amino acid sequences of Pre. intermedia BAU17746 (Pi BAU17746), T. forsythia putative dipeptidase (Tf dipeptidase A), L. helveticus dipeptidase A (Lh dipeptidase A), and S. gordonii Arg-aminopeptidase (Sg Arg-aminopeptidase) were compared. Identical amino acids are marked by an asterisk, and strongly and weakly similar amino acids are marked by colons and dots, respectively. Cysteines (red letters) essential for the activity are boxed (see text). N-terminal amino acid sequences were determined by sequencing of 54- and 56-kDa forms of BAU17746 are indicated by arrows. Thirty-five truncated residues in BAU17746 $\Delta$ N1-35 are underlined with a broken line.
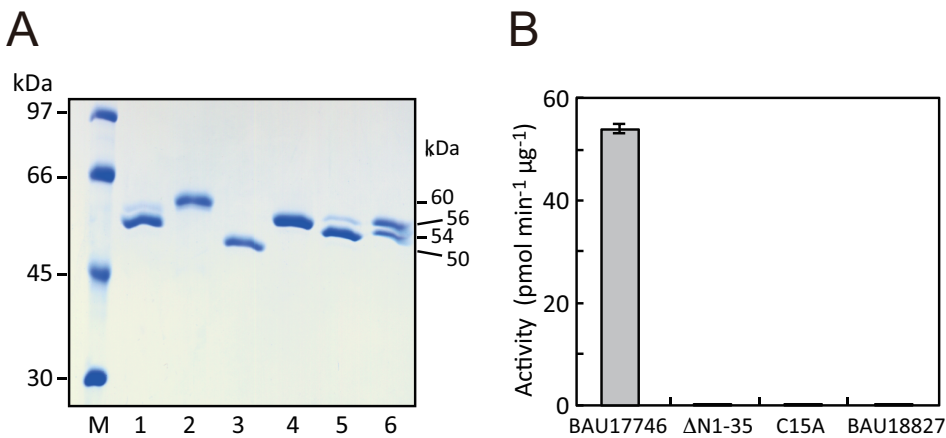

\begin{tabular}{|c|c|c|c|c|c|c|c|}
\hline \multirow[b]{2}{*}{ Species } & \multicolumn{6}{|c|}{ Observed amino acids } & \multirow[t]{2}{*}{ Deduced sequence } \\
\hline & 1 & 2 & 3 & 4 & 5 & 6 & \\
\hline $54 \mathrm{kDa}$ & $x$ & Thr & Thr & Met & Ile & Val & Cys $^{15}$-Thr-Thr-Met-Ile-Val ${ }^{20}$ \\
\hline \multirow[t]{4}{*}{56 kDa } & Gly & Gly & Ser & Met & Lys & Glu & gly $^{-3}$-gly-ser-Met-Lys-Glu ${ }^{3}$ \\
\hline & Met & Lys & Glu & Asn & Ile & Val & Met $^{1}$-Lys-Glu-Asn-Ile-Val ${ }^{6}$ \\
\hline & $(X)$ & Thr & Thr & (Met) & (Ile) & (Val) & Cys $^{15}$-Thr-Thr-Met-Ile-Val ${ }^{20}$ \\
\hline & Ser & Ser & & & Glu & & unidentified \\
\hline
\end{tabular}

Figure 4 Expression and activity of recombinant proteins.

(A) Recombinant proteins $(1 \mu \mathrm{g})$ of BAU17746 (lanes 1 and 5), BAU18827 (lane 2), BAU17746 $\triangle \mathrm{N} 1-35$ (lane 3), BAU17746C15A (lane 4), and a mixture (0.5 $\mu \mathrm{g}$ each) of BAU17746 and BAU17746C15A (lane 6) were separated with SDS-PAGE. Lane M, lowmolecular-weight marker. (B) Peptidase activities of BAU17746, BAU17746 1 N1-35, BAU17746C15A, and BAU18827 were determined with Arg-MCA. Values are shown as the mean \pm S.D. $(\mathrm{n}=3)$. (C) N-terminal sequencing of 54- and 56-kDa species of BAU17746. Vector-derived amino acids are shown with small letters. 
A

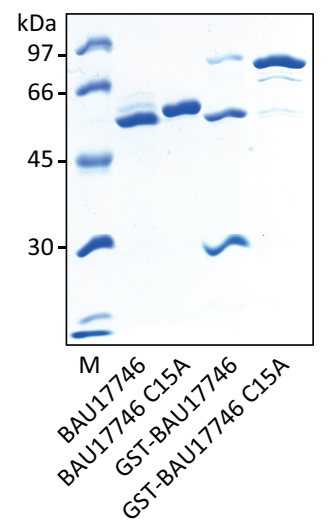

B

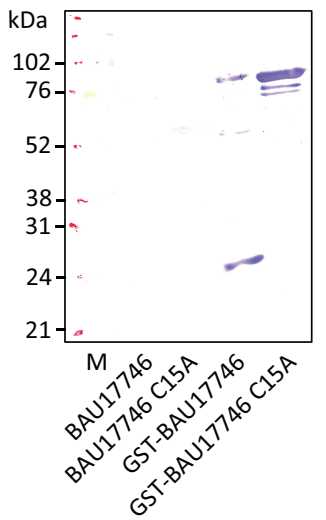

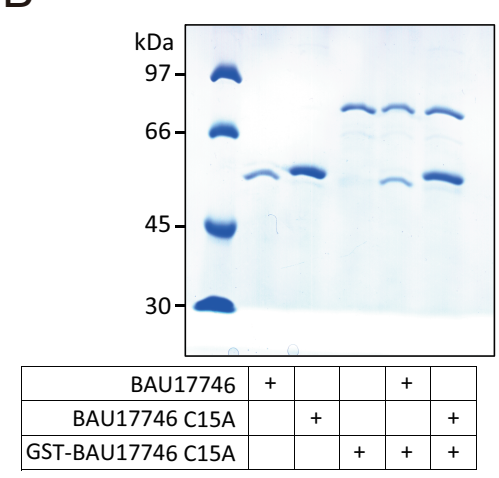

Figure 5 Effect of the Cys15Ala mutation on the processing of BAU17746.

(A) Recombinant proteins (left, $1 \mu \mathrm{g}$; right, $0.3 \mu \mathrm{g}$ ) were separated with SDS-PAGE and stained with CBB (left) or by immunoblotting with an anti-GST antibody (right). Low-molecular-weight markers (left) and full-length molecular markers (right) were used. (B) Recombinant proteins $(0.2 \mathrm{mg} / \mathrm{ml}$ each, $40 \mu \mathrm{l})$ were incubated at $37^{\circ} \mathrm{C}$. After $5 \mathrm{~h}$, proteins were denatured in the SDS buffer and proteins (1 $\mu \mathrm{g}$ of each) were separated on SDS-PAGE.

A

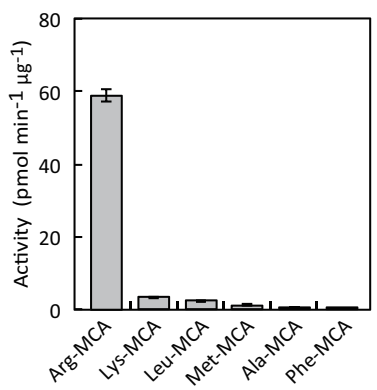

$\mathrm{D}$

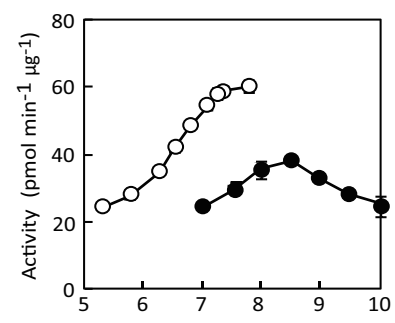

$\mathrm{B}$

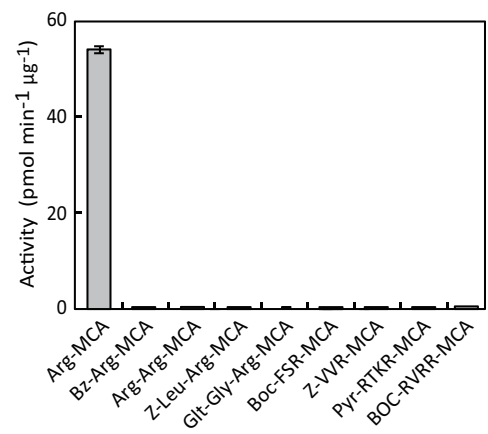

$E$

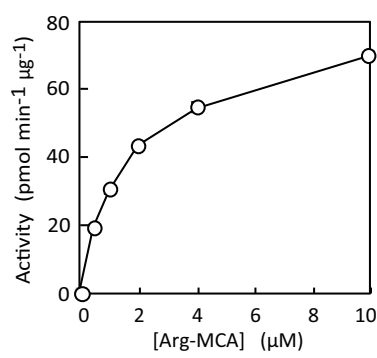

$\mathrm{F}$
C
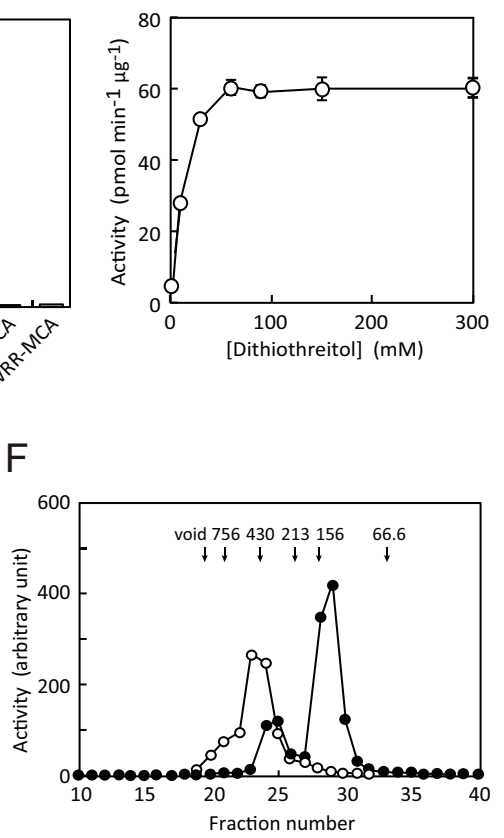

Figure 6 Properties of BAU17746.

(A) Aminopeptidase and (B) peptidase activities toward peptides containing Arg at the P1 position were determined with recombinant BAU17746. (C) Arg-MCA-hydrolyzing activity of BAU17746 was determined at $0-300 \mathrm{mM}$ dithiothreitol. (D) $\mathrm{pH}$ profile of Arg-MCAhydrolyzing activity with sodium phosphate (open circle) and Tris-HCl (closed circle) buffers. (E) Concentration dependence of Arg-MCA hydrolysis was determined. Values are shown as the mean \pm S.D. $(\mathrm{n}=3)$. (F) BAU17746 $(0.5 \mathrm{mg} / 0.5 \mathrm{ml}$, open circle) and Pre. intermedia cell lysate containing cytosol and periplasm fractions $(0.5 \mathrm{ml}$, closed circle $)$ were separately subjected to size-exclusion HPLC with a Superdex 200 10/300 column. Activity was determined with ArgMCA. Molecular markers shown running in parallel are blue dextran 2000 (void volume), thyroglobulin $(756 \mathrm{kDa})$, ferritin $(430 \mathrm{kDa})$, catalase $(213 \mathrm{kDa})$, aldolase $(156 \mathrm{kDa})$, and BSA $(67 \mathrm{kDa})$. 
A

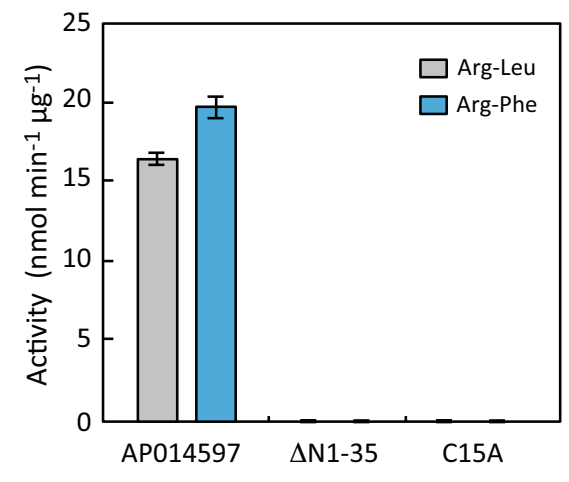

$\mathrm{B}$

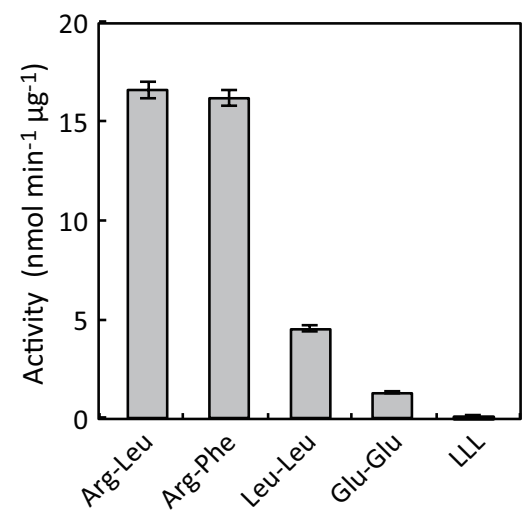

Figure 7 Dipeptidase activity of recombinant peptidases.

(A) BAU17746, BAU17746 $\triangle \mathrm{N} 1-35$, and BAU17746C15A dipeptidase activities were determined with $0.3 \mathrm{mM}$ dipeptides using a ninhydrin method, as described in the Materials and methods. (B) Substrate specificity of BAU17746 was determined with $0.3 \mathrm{mM}$ di- and tripeptides. Values are shown as the mean \pm S.D. $(n=3)$.
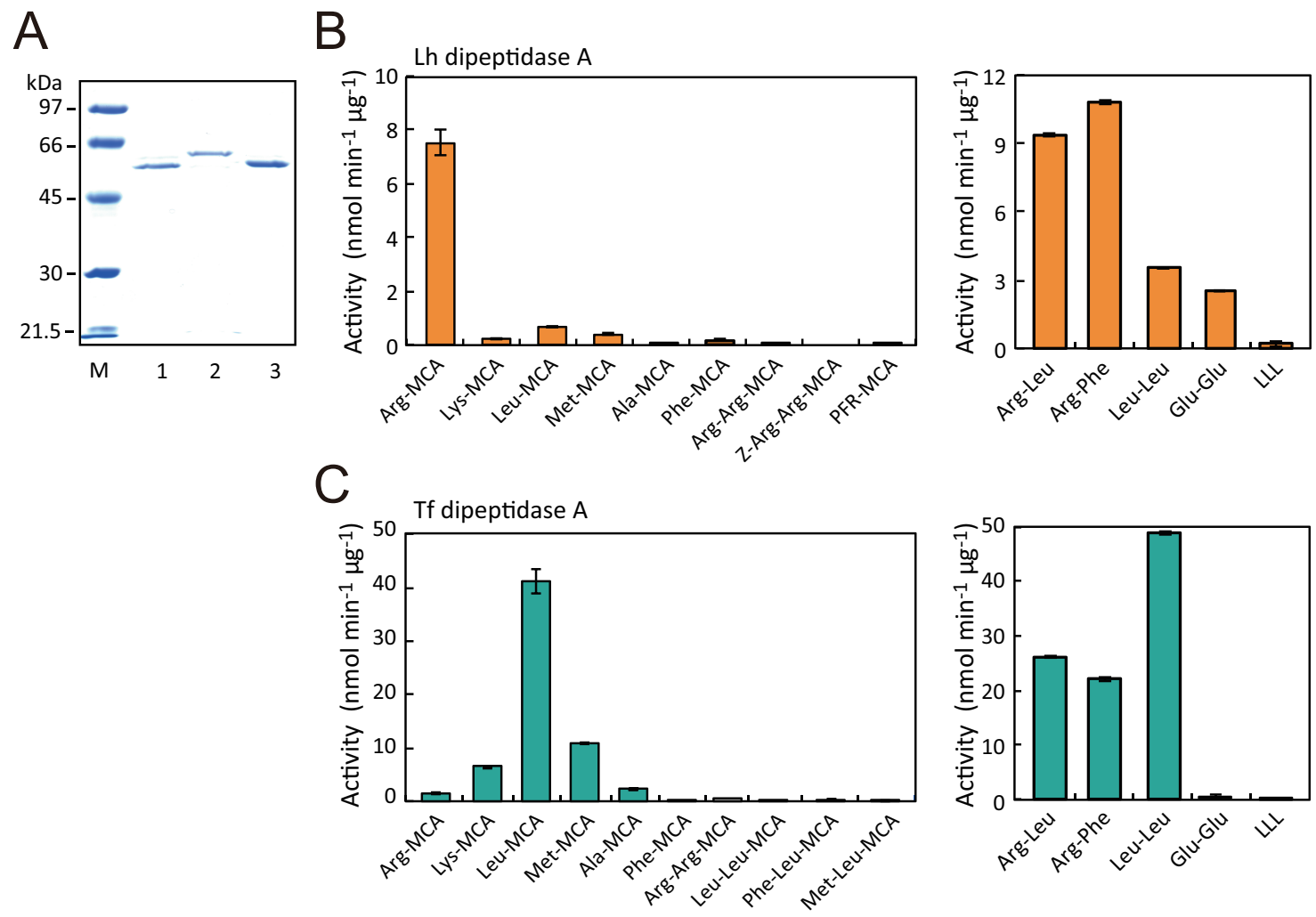

Figure 8 P1-position specificity of L. helveticus and T. forsythia dipeptidases.

(A) Recombinant proteins (1 $\mu \mathrm{g}$ ) of BAU17746 (lane 1), L. helveticus dipeptidase A (lane 2), and T. forsythia dipeptidase (lane 3) were separated with SDS-PAGE. Lane M, low-molecular-weight marker. (B) Peptidase activity of L. helveticus dipeptidase A was determined with $20 \mu \mathrm{M}$ aminoacyl-MCA (left) and $0.3 \mathrm{mM}$ di- and tri-peptides (right). (C) Peptidase activity of $T$. forsythia dipeptidase was determined with $20 \mu \mathrm{M}$ aminoacyl-MCA (left) and $0.3 \mathrm{mM}$ di- and tripeptides (right). Values are shown as the mean \pm S.D. $(n=3)$. 
A

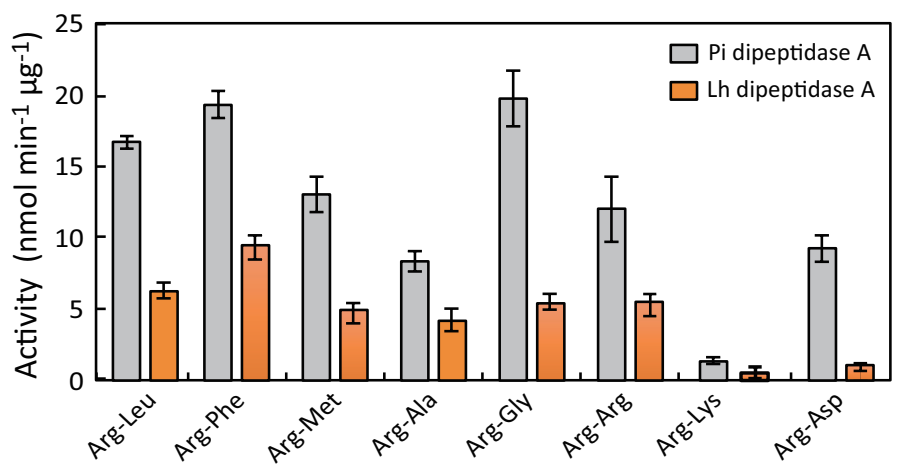

B

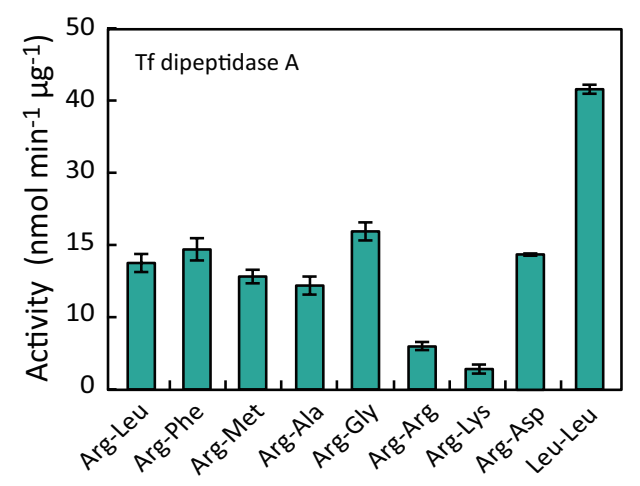

Figure 9 P1'-position specificity of recombinant dipeptidases.

Dipeptidase activities of (A) BAU17746 and L. helveticus dipeptidase A, and (B) T. forsythia dipeptidase were determined with $0.3 \mathrm{mM}$ dipeptides harbouring $\mathrm{Arg}$ at the $\mathrm{N}$-terminus. Additionally, the activity of $T$. forsythia dipeptidase A was determined with $0.3 \mathrm{mM}$ Leu-Leu (presented in panel B). Values are shown as the mean \pm S.D. $(n=3)$. 